\title{
The Difference of Bovine Bone Graft and Iliac Crest Bone Graft Effect on Closure of Bone Defect in Alveolar Bone Graft in Dr. Moewardi Hospital and Panti Waluyo Hospitals, Surakarta
}

\author{
Ruzbih Bahtiar'1), Dewi Haryanti Kurniasih²), Untung Alifianto3) \\ 1)Department of Surgery, Dr. Moewardi Hospital, Surakarta/ \\ Faculty of Medicine, Universitas Sebelas Maret \\ 2)Department of Plastic Surgery, Dr. Moewardi Hospital, Surakarta/ \\ Faculty of Medicine, Universitas Sebelas Maret \\ 3)Department of Neurological Surgery, Dr. Moewardi Hospital, Surakarta/ \\ Faculty of Medicine, Universitas Sebelas Maret
}

\begin{abstract}
Background: Cleft lip and palate (CLP) is a case of craniofacial congenital abnormalities that are often found by plastic surgeons. Successful management requires good surgical techniques, deep understanding of anatomical abnormalities and three-dimensional aspects of facial aesthetics. The Alveolar bone graft (ABG) aims to unite and stabilize Maxilla before definitive orthodontic action and restoration of dental care. The use of bone grafts in the surgical field is often done, aimed at maximizing the process of bone healing. Autogenous bone graft is the gold standard bone graft material because it contains all the properties needed in bone formation. The iliac crest bone graft (ICBG) is the most commonly used donor. Bromine bone graft (BBG) is increasingly being used as a substitute for autogenous bone graft. The purpose of this study was to determine the differences in the effect of the percentage of defect closure between CNG and ICBG on the closure of defects in ABG.

Subjects and Method: The retrospective cohort study was conducted at Dr. Moewardi and Panti Waluyo Hospitals, Surakarta, Central Java, Indonesia, from February to April 2018. The dependent variable was bone defect closure. The independent variables were bovine bone and iliac crest bone grafts. The data were analyzed by Mann-Whitney.

Results: Most patients after ABG surgery have a percentage of bone defect closure of $75-100 \%$ with bone resorption of $0-25 \%$ and include type I Bergland scale, where ICBG (66.7\%) tends to be better than BBG (55.6\%), but statistically not significant ( $\mathrm{p}$ value $=0.678$ ).

Conclusion: There is no difference in the effect of the percentage of defect closure between CNG and ICBG on the closure of defects in ABG. ICBG tends to give a better percentage of defect closure than $\mathrm{CNG}$, but it is not statistically significant.
\end{abstract}

Keywords: Cleft lip and palate (CLP), Alveolar bone graft, bovine bone graft, Iliac crest bone graft, closure of bone defects.

\section{Correspondence:}

Ruzbih Bahtiar. Department of Surgery, Dr. Moewardi Hospital, Surakarta/Faculty of Medicine, Universitas Sebelas Maret.

\section{BACKGROUND}

Cleft lip and palate (CLP) or cleft lip and groin are cases of congenital cranio-facial abnormalities that are often found by plastic surgeons. Successful management in this case requires good surgical techniques, a deep understanding of anatomical abnor- malities and an understanding of the threedimensional aspects of facial aesthetics. Management of CLP requires collaboration from a team consisting of multi-disciplines, including Plastic Surgeons, Orthodontists, ENT experts and speech therapists. Each specialization has a role that does not overlap but is complementary in dealing with 
CLP sufferers in a complete manner (Marzoeki et al., 2002).

In CLP patients, there is an increased incidence of dental anomalies due to a disruption of the tooth growth process due to bone defects in the CLP area, including impacted teeth, agenesis, super-numerary teeth (overgrowth of teeth), developmental delay, and changes in crown ratio teeth with tooth roots. Therefore, closure of bone defects in CLP patients is needed to prevent these anomalies (Vuletic et al., 2014).

At this time, the use of bone grafts in handling trauma or non-trauma in the surgical field is often done, with the aim of maximizing bone healing processes. The function of the bone graft is as osteoconductive, osteoinductive and osteogenic (Myeroff, Archdeacon, 2011). In addition, there are several other goals and advantages of Alveolar bone grafting, namely to maintain arcus continuity Maxillaris, maximizing bone support in the tooth growth process, stabilizing the Maxilla segment after orthodontic therapy, removing the oronasal fistula, providing nasal alar cartilage support, forming morphology Alveolar is ideal, and ensures the availability of bone with attached soft tissue for the installation of endosteal implants if there is still remaining tooth space (Vuletic et al., 2014).

There are several kinds of usage techniques and sources of bone grafts, namely bone grafts that can originate from the same body (autogenousbone graft), allografts (which come from donors / the same species), and xenografts namely grafts from animals. In addition, there are also syntheticbone substitutes (ie those from factory-made) and can be used with a variety of techniques including single use, or with combinations and additions of certain ingredients such as Hidroxyapatite.
The choice of donor site for closure of the Alveolar cleft defect initially had many choices, with Tibia bone being a bone graft first used for Drachter's palatoplasty in 1914. However, since the secondary Alveolar bone graft was first performed by Boyne and Sand in 1972, this technique was then accepted and developed as the most common choice in order to unite and stabilize Maxilla before definitive orthodontic action and restoration of dental care. Ideally, this technique is done at an earlier age to allow canines to grow on the graft bone. For this reason, cancellous bone graft is preferred over cortical or costochondral bone graft (Kinderlan et al., 1997).

Autogenousbone graft is considered the gold standard for bone graft material because it contains all the properties needed in bone formation: osteoinduction (BMP and other growth factors), osteogenesis (osteo-progenitor cells) and osteoconduction. It is widely used in a number of orthopedic procedures and Maxillofacial procedures for the formation and acceleration of bone regeneration (fusion, non-union, fracture and healing after osteotomy) or repair of bone defects (trauma, congenital abnormalities, tumors or infections). Because it is taken from the patient itself, auto-genous bone is histocompatible and nonimmunogenic, thereby reducing the possibility of infection and transmission of the immunoreaction (Dimitriou et al., 2011).

Autogenous bone graft derived from Iliaca bone (Iliac crestbone graft / ICBG) is the area most often taken and used widely. The cortical, corticocancellous, or cancellous bone segments of large Iliaca bone can be taken quickly to cover a variety of defects, supported by a location that allows donor retrieval to be carried out by a separate team. Bone grafting that has been carried out so far shows good long-term endurance and enables rehabilitation with 
osseo-integrated dental implants. However, the rate of bone unification decreases dramatically if the defect is more than $6 \mathrm{~cm}$ in size, and the level of morbidity in the donor site of the Iliac crest graft is $23 \%$ (Elsalanty, Genecov, 2009). Potential complications of the ICBG include chronic pain, walking disorders, paresthesia, vascular injury, pathological fractures, herniation, hematoma, infection and cosmetic deformity. For its own level of success, Long et al. in 1995 performed radiographic bone graft measurements on 46 cases of CLP to measure bone filling by using x-rays taken after 6 months and obtaining new bone formation in $91 \%$ of cases (Kinderlan et al., 1997).

There are limitations in the use of autografts, and the high need to deal with patients both trauma and non-trauma is the basis in an effort to find other alternatives to autogenousbone grafts. Limitations of autograft use in cases of pediatrics and geriatrics, as well as in certain cases where the quality of autograft is not good (in osteopenia) or in osteoporotic bone, neurofibromatosis, post radiation and in degenerative cases, also morbidity persists in the use of autografts, increasingly encouraging efforts to find other alternatives in its handling. At present, the use of bovinebone graft (CNG) in the treatment of bone defects has been widely used and is an alternative because of its abundant and abundant availability and difficult processing and making it an alternative treatment for bone defects. It is well known, that the microstructure composition is also almost similar to humans. In addition cancellous CNG also contains high levels of calcium and phosphorus (Wang, 2003). However, until now there is no journal or scientific literature that reveals the success rate of Alveolarbone graft (ABG) using CNG.

The purpose of this study was to determine the effect of the percentage of defect closure between CNG and ICBG on the closure of defects in $\mathrm{ABG}$, and to determine whether the ICBG results in a better percentage of bone defect closure than CNG.

\section{SUBJECTS AND METHOD}

This was a retrospective cohort study, conducted at the SMF Surgical, dr. Moewardi and Panti Waluyo Hospitals, Surakarta, from February to April 2018.

The subjects in this study were all patient medical record data carried out by in dr. Moewardi and Panti Waluyo Hospitals from January 2014 to July 2017.

The dependent variable was bone defect closure. The independent variables were bovine bone and iliac crest bone grafts.

The closure of the bone defect measured in this study was the percentage of closed defects in Alveolar bone after the ABG was performed, with the X-ray Orthopantomogram (OPG) instrument, where the assessment was compared with pre-OPG Xray and post-op $\mathrm{ABG}$, and the percentage of closure defects was assessed by using the Bergland scale (Figure 1). The data were analyzed by Mann Whitney. 


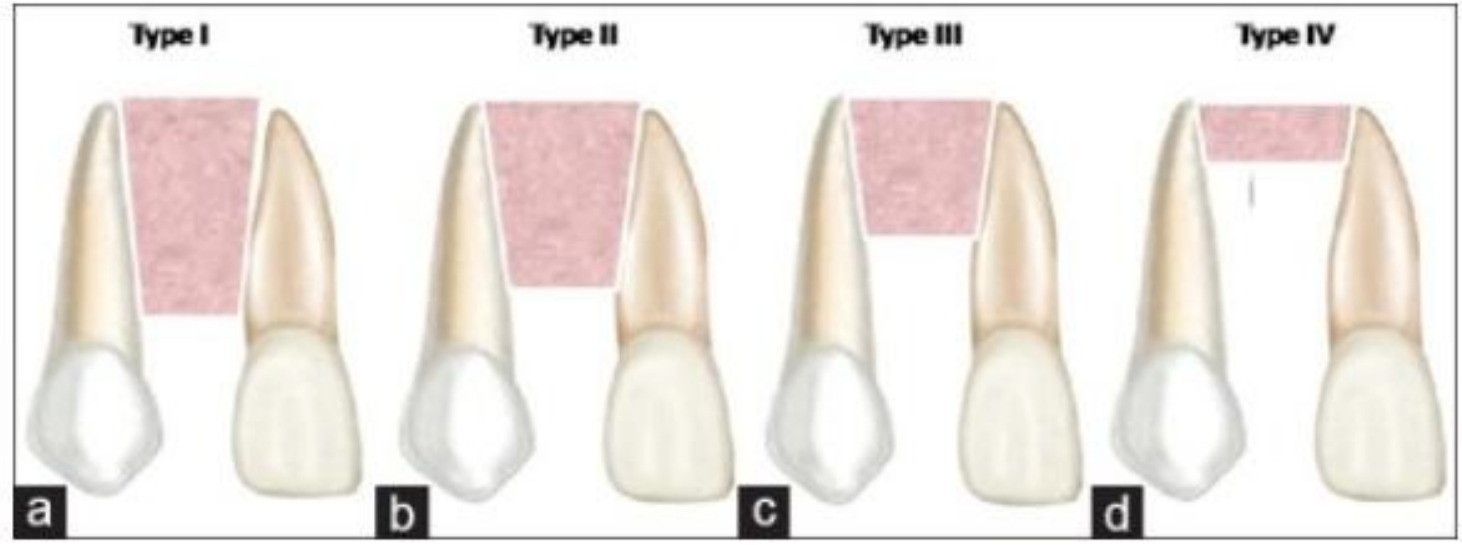

Figure 1. Bergland scale

(a) Type I: 0\%-25\% resorpsi tulang. (b) Type II: 25\%-50\%. (c) Type III: 50\%-75\%. (d) Type IV: 75\%-100\% without the reinforcement bridge passing cleft (Aly, Hammouda, 2016).

\section{RESULTS}

This study was conducted on 15 patients who had been performed by ABG in Dr. Moewardi and Surakarta Panti Waluyo
Hospitals with 2 different treatments, with 6 patients with CNG and 9 patients with ICBG, with the following results.

Table 1. Sample characteristics

\begin{tabular}{llllclc}
\hline Gender & \multicolumn{1}{c}{ Diagnosis } & & Action & $\begin{array}{c}\text { Age } \\
\text { (years) }\end{array}$ & Complication & $\begin{array}{c}\text { Closing } \\
\text { of Defect } \\
\text { (\%) }\end{array}$ \\
\hline Male & Labiognatopalatoschizis & Incomplete & ICBG & 3 & No & $50-75$ \\
Male & Labiognatopalatoschizis & Complete & ICBG & 4 & Fistel Palatum & $75-100$ \\
Male & Labiognatopalatoschizis & Complete & ICBG & 4 & Fistel Palatum & $75-100$ \\
Male & Labiognatopalatoschizis & Complete & BBG & 4 & Fistel Palatum & $75-100$ \\
Male & Labiognatoschizis & Incomplete & BBG & 17 & No & $50-75$ \\
Female & Labiognatoschizis & Complete & ICBG & 5 & No & $75-100$ \\
Male & Labiognatopalatoschizis & Complete & BBG & 3 & Fistel Palatum & $50-75$ \\
Male & Labiognatopalatoschizis & Incomplete & ICBG & 4 & No & $75-100$ \\
Male & Labiognatopalatoschizis & Complete & BBG & 3 & No & $50-75$ \\
Male & Labiognatopalatoschizis & Complete & BBG & 9 & No & $75-100$ \\
Male & Labiognatopalatoschizis & Complete & BBG & 5 & No & $75-100$ \\
Male & Labiognatopalatoschizis & Complete & ICBG & 5 & No & $50-75$ \\
Male & Labiognatopalatoschizis & Complete & BBG & 6 & No & $75-100$ \\
Female & Labiognatopalatoschizis & Complete & BBG & 5 & No & $75-100$ \\
Male & Labiognatoschizis & Complete & BBG & 6 & No & $50-75$ \\
\hline
\end{tabular}


Bahtiar et al./ The Difference of Bovine Bone Graft and Iliac Crest Bone Graft

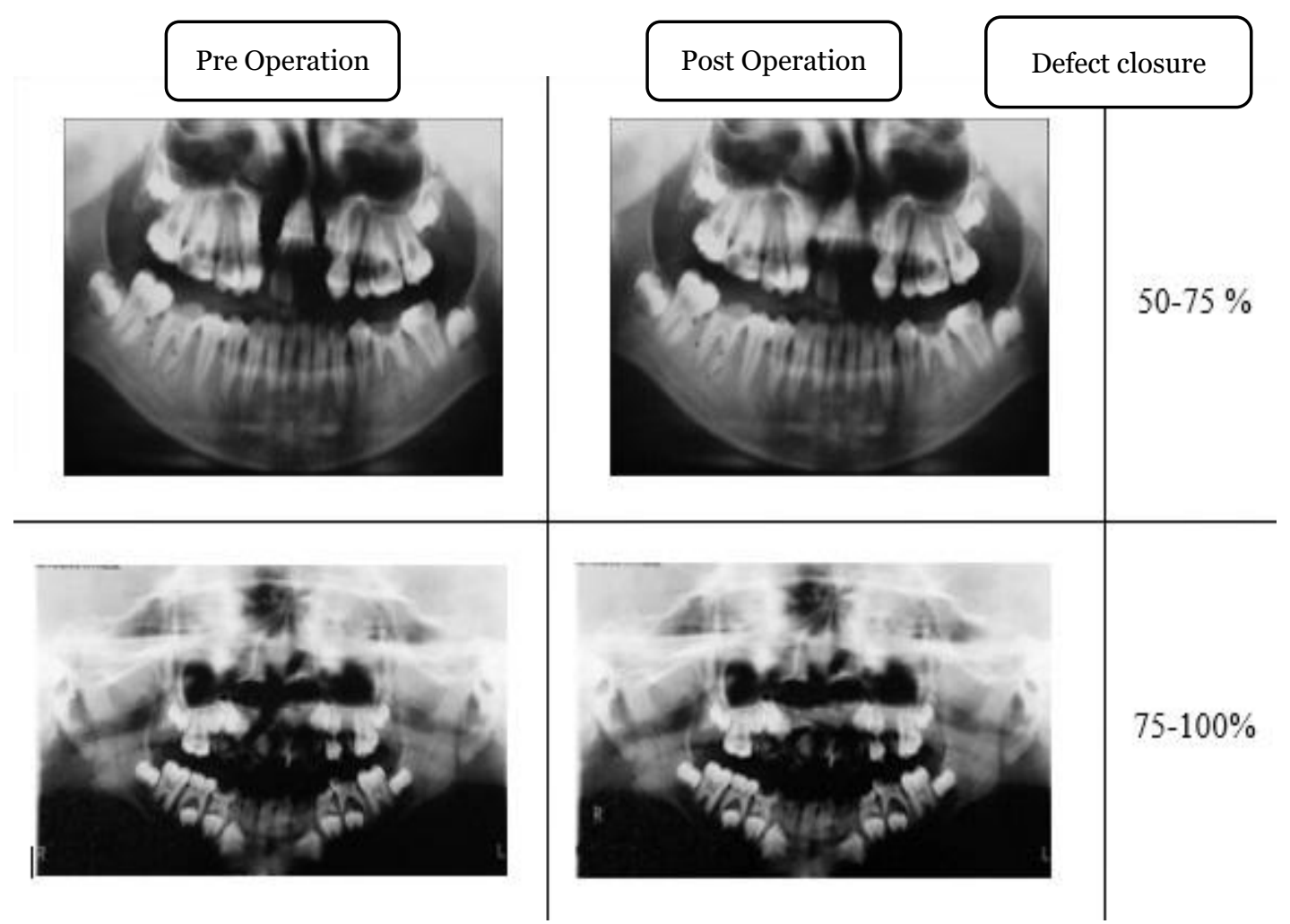

Figure 2. Rontgen OPG pre op and post op of the patients undergoing CNG action

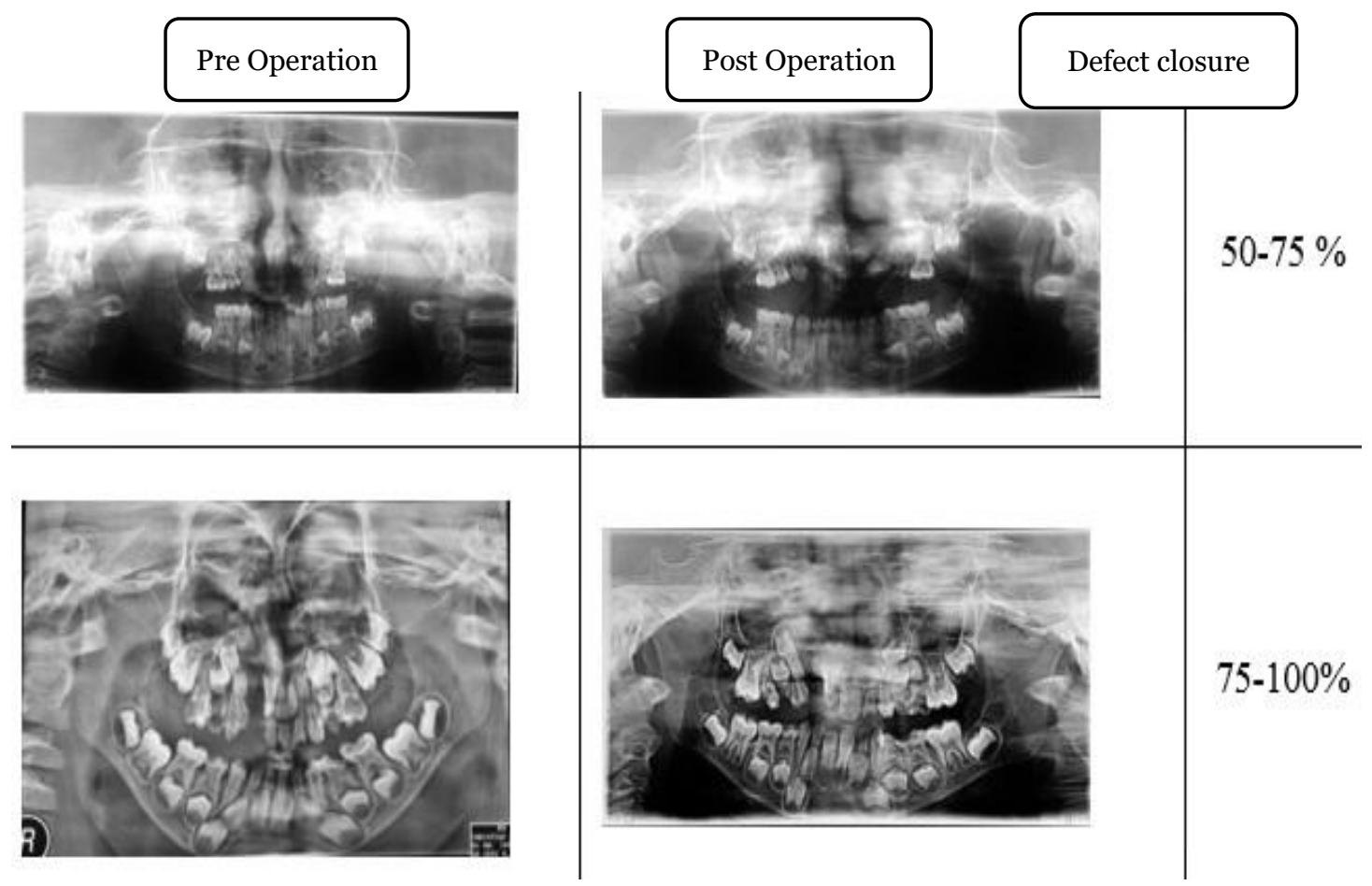

Figure 3. OPG Pre Op and Post Op X-ray of patients undergoing ICBG action 
Indonesian Journal of Medicine (2018), 3(3): 151-161

https://doi.org/10.26911/theijmed.2018.03.03.05

Table 2. Bivariate analysis using Chi square

\begin{tabular}{|c|c|c|c|c|}
\hline \multirow[b]{2}{*}{ Variable } & \multicolumn{2}{|c|}{ Action } & \multirow[b]{2}{*}{$\begin{array}{c}\text { Total } \\
(n=15)\end{array}$} & \multirow[b]{2}{*}{$\mathbf{p}$} \\
\hline & $\begin{array}{c}\text { Iliac } \\
(n=6)\end{array}$ & $\begin{array}{c}\text { Bovine } \\
(n=9)\end{array}$ & & \\
\hline Gender & & & & 1.000 \\
\hline Male & $5(83.3 \%)$ & $8(88.9 \%)$ & $13(86.7 \%)$ & \\
\hline Female & $1(16.7 \%)$ & $1(11.1 \%)$ & $2(13.3 \%)$ & \\
\hline Age & & & & 0.103 \\
\hline 3-6 years & $6(100.0 \%)$ & $5(55.6 \%)$ & $11(73 \cdot 3 \%)$ & \\
\hline$>6$ years & o (o.o\%) & $4(44.4 \%)$ & $4(26.7 \%)$ & \\
\hline Type of schizis & & & & 1.000 \\
\hline Labiognatopalatoschizis & $5(83.3 \%)$ & $7(77.8 \%)$ & $12(80.0 \%)$ & \\
\hline Labiognatoschizis & $1(16.7 \%)$ & $2(22.2 \%)$ & $3(20.0 \%)$ & \\
\hline Cleft & & & & 0.525 \\
\hline Incomplete & $2(33 \cdot 3 \%)$ & $1(11.1 \%)$ & $3(20.0 \%)$ & \\
\hline Complete & $4(66.7 \%)$ & $8(88.9 \%)$ & $12(80.0 \%)$ & \\
\hline Complication & & & & 1.000 \\
\hline None & $4(66.7 \%)$ & $7(77.8 \%)$ & $11(73 \cdot 3 \%)$ & \\
\hline Fistel Palatum & $2(33.3 \%)$ & $2(22.2 \%)$ & $4(26.7 \%)$ & \\
\hline
\end{tabular}

Based on table 2, it showed that the majority of patients were male, who were 13 patients $(86.7 \%)$, and the rest were female, who were 2 patients (13.3\%). From the calculation, the score of puntuk gender was 1,000 ( $p>0.05$ ) which mean that there was no significant difference in patients who got ICBG treatment and BBG based on gender.

Based on the age of the patient, it was found that most of them were 3-6 years old, which were 11 patients (73.3\%), and the rest were $>6$ years old, who were 4 patients (26.7\%). From the calculation, the age value was 0.103 ( $p>0.05$ ) which mean that there was no significant difference in patients who got ICBG treatment with BBG based on age.

Based on the diagnosis of schizis type, it was found that the majority of patients were diagnosed with Labiognatopalatoschizis, who were 12 patients (80.0\%), and the rest with Labiognatoschizis who were 3 patients (20.0\%). From the calculation, the score of schizis diagnosis was 1,000 ( $p>$ 0.05) which mean that there was no significant difference in patients who got ICBG treatment with BBG based on schizis type.

Based on the complete/ incomplete cleft, it was found that the patients were mostly complete cleft, who were 12 patients (80.0\%), and the rest with complete cleftin were 3 patients $(20.0 \%)$. From the calculation, it was found that the value of complete/incomplete cleft was 0.525 ( $p>$ 0.05) which mean that there was no significant difference in patients who got ICBG treatment with BBG based onthe complete/ incomplete cleft.

Based on postoperative complications, it was known that the majority of patients did not experience complications, who were 11 patients (73.3\%), and the rest experienced complications in the form of palate fistula were 4 patients (26.7\%). From the calculations, the $\mathrm{p}$ value for postoperative complications was 1.000 ( $p>0.05$ ) which mean that there was no significant difference in patients who got ICBG treat- 
ment with BBG based on complications of postoperative surgery.

Based on the description above, it was known that the basic characteristics of the study subjects between patients who got ICBG and BBG were homogeneous.

In this study, to find out the results of a better percentage of bone defect closure

Table 3. The difference in percentage of bone defect closure between ICBG treatment groups and BBG

\begin{tabular}{|c|c|c|c|c|c|}
\hline \multirow[b]{2}{*}{ Type } & \multirow{2}{*}{$\begin{array}{l}\text { Bone Defect } \\
\text { Closure }\end{array}$} & \multicolumn{2}{|c|}{ Action } & \multirow[b]{2}{*}{$\begin{array}{c}\text { Total } \\
(n=15)\end{array}$} & \multirow[b]{2}{*}{$\mathbf{p}$} \\
\hline & & $\begin{array}{l}\text { Iliac } \\
(n=6)\end{array}$ & Bovine $(n=9)$ & & \\
\hline IV & $0 \%-25 \%$ & $\mathrm{o}(0 \%)$ & o (o\%) & o (o\%) & 0.678 \\
\hline III & $25 \%-50 \%$ & o (o\%) & o (o\%) & o (o\%) & \\
\hline II & $50 \%-75 \%$ & $2(33.3 \%)$ & $4(44.4 \%)$ & $6(40 \%)$ & \\
\hline $\mathrm{I}$ & $75 \%-100 \%$ & $4(66.7 \%)$ & $5(55.6 \%)$ & $9(60 \%)$ & \\
\hline
\end{tabular}

The results showed that most patients after ABG surgery had a percentage of bone defect closure of $75 \%-100 \%$, which mean that bone resorption was $0-25 \%$ and included in the type I group based on the Bergland scale, with the proportion in the ICBG group (66.7\%) more than CNG between ICBG and BBG was by using the Xray Orthopantomogram instrument, it was assessed by using the Bergland scale with categories (a) Type I: o\% $-25 \%$ bone resorption. (b) Type II: 25\%-50\%. (c) Type III: 50\%-75\%. (d) Type IV: 75\%-100\%.

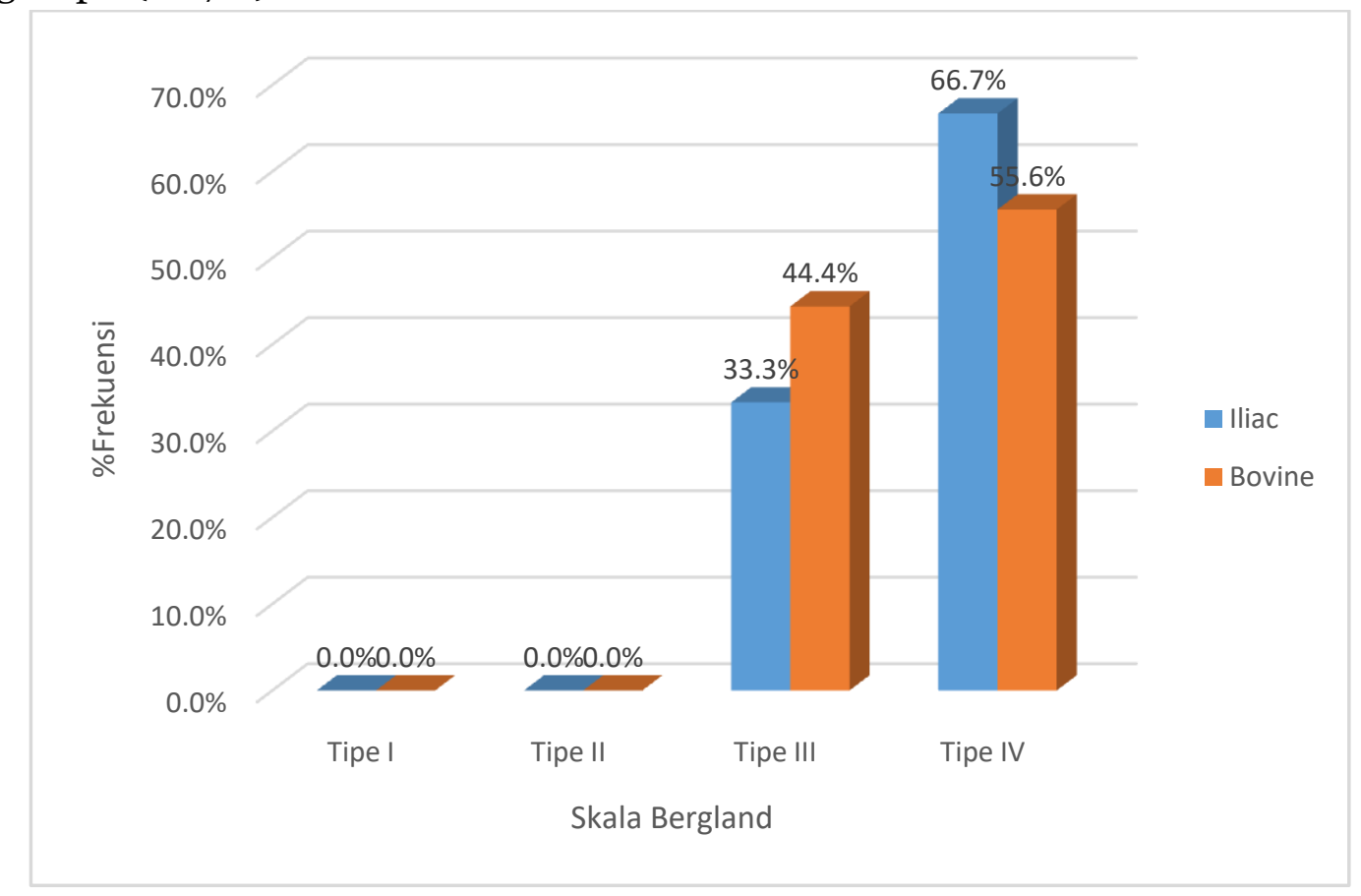

Figure 4. Bar chart percentage of the closure of bone defects between ICBG and BBG 
Relationship between the characteristics of respondents with percentage of closure of bone defects

This additional analysis was aimed to find out sample characteristics with the percent-

Table 4. The relationship of respondent characteristics with percentage of bone defect closure (description: contingency coefficient test)

\begin{tabular}{lcc}
\hline \multicolumn{1}{c}{ Independent Variables } & \multicolumn{2}{c}{ Bone Defect Closure } \\
\cline { 2 - 3 } & $\mathbf{r}$ & $\mathbf{p}$ \\
\hline Gender & 0.305 & 0.215 \\
Age & 0.122 & 0.634 \\
Diagnosis & & \\
Schizis Type & 0.263 & 0.292 \\
Complete/Incomplete & 0.263 & 0.292 \\
\hline
\end{tabular}

Based on table 4, it was known that the scores of gender, age and diagnosis variables were $0.215,0.634$ and 0.292 ( $p>0.05)$, which mean that the basic characteristics of patients based on gender, age and diagnosis have no significant effect on percentage of bone defect closure in patients who got ABG in dr. Moewardi and Panti Waluyo Surakarta Hospitals.

The results of this study showed that there was no difference in the effect of percentage of bone defect closure between ICBG and BBG. The ICBG produced a better result than BBG, but it was not statistically significant, where the proportion in the ICBG group (66.7\%) was greater than BBG (55.6\%). This can lead to statistically insignificant results that were microstructure of bovine graft which was almost similar to humans, causing the process of fusing BGG which was an xenograft into the recipient site and has a similar result to ICBG which was an autogenous bone graft, because from the patient's own body, it was histocompatible with immunogenic conditions, thereby reducing the possibility of infection transmission (Nascimento et al., 2007, Dimitriou et al., 2011).

There were several factors which related to bone graft masters to recipient sites, including the type of graft, porosity, age of bone defect closure. Based on the results of the study, the following results were obtained. and mechanism of action of the graft. Cancellous and corticocancellous autogenous grafts have a better unification process because they have a porous structure, allowing easy cellular and vascular invasion. Trabecula graft has a large surface area covered with osteoblasts, allowing osteogenic and three-dimensional osteoconductive growth. In addition, because of the extent of vascular invasion, the bone matrix can be demineralized and its protein exposed to osteoclasts and caused the release of osteoinductive protein matrix.

Another important factor that determined graft unification was vascularization and viability of the graft bed. Bone grafts usually need to be attached to the bleeding edge of the living bone. Excessive heat during the cutting process with a saw can cause necrosis of the bone edge and inhibit the unification with the graft. Radiotherapy can harm tissue vascularization, eliminating reconstruction options by using a nonvascularized bone graft. In such cases, a vascularized bone graft must be used, so that the viable edge of the bone can be connected to the graft, blood vessels can be used as microvascular anastomoses, and there was no infection. Some studies suggested the use of hyperbaric oxygen therapy to promote tissue perfusion before 
reconstruction. Finally, the union of grafts also depend on the overall physiological healing capacity of the body (Elsalanty, Genecov, 2009).

Another thing that can cause a statistically insignificant percentage of defect closure between ICBG and BBG was the presence of high calcium and phosphorus and was absorbed more quickly on BBG, which would cause minimal bone resorption and allowed adequate closure of bone defects. In addition with the ingredients of Hydroxyiapatite on CNG which was a bone substitute that has a chemical, biological, and microstructural position that was similar to human bone, has good enough osteoconductive properties and excellent biocompatibility would further support the success of defect closure Alveolar bone in patients who conducted ABG surgery (Nascimento et al., 2007, Dimitriou et al., 2011).

The results of the study also showed that the majority of patients (73.3\%) who conduct $\mathrm{ABG}$ did not experience complications, whereas in $26.7 \%$ of patients (4 people) a postoperative complication was formed in the form of a palate fistula by 2 patients both on ICBG and BBG. Although there was no significant difference from the statistical calculations in patients who got ICBG treatment with BBG for complications of postoperative surgery, the occurrence of the palate fistula was common in patients who conduct ABG. There were several causes of this complication.

Wiedel et al. (2015) stated that there was a clear relationship between the cleft width of Alveolar and the occurrence of postoperative dehiscence, where the wider the cleft, the greater the likelihood of dehiscence. This was because in the wide cleft, it would be highly difficult to mobilize the mucoperium fluid to provide complete wound closure without causing graft tension. In addition, the cleanliness of the oral cavity was also a factor that determined the emergence of these complications, where patients with poor oral hygiene would facilitate the occurrence of postoperative infections in the wound, which in turn would cause the emergence of the palate fistula. However, this can be anticipated by the use of adequate anti-septic mouthwash, administration of additional antibiotics, and wound care with the aim of suppressing granulation tissue by administering silver nitrate locally. However, considering that ABG surgery was performed on pediatric patients, there would be difficulties in the form of patient non-compliance to carry out this anticipatory therapy. However, the problem of healing these wounds that can cause the palate fistula after ABG surgery would not definitely cause a failure in the results of the defect closure, which was also shown in this study (Wiedel et al., 2015).

Therefore, BBG can be used as an alternative to ICBG in the treatment of Alveolar bone defects, where the results of this study have shown no significant differrences between the use of ICBG and BBG on the percentage of bone defect closure.

Based on the results of this study, it can conclude that there was no difference in the effect of the percentage of defect closure between bovine bone graft and Iliac crest bone graft on the closure of defects in Alveolarbone graft.

Iliac crestbone graft tend to produce a better percentage of defect closure compared to bovine bone graft, but it was not statistically significant.

\section{REFERENCES}

Aly LAA, Hammouda N (2016). Secondary closure of Alveolar cleft with resorbable collagen membrane and a combination of intraoral autogenous bone graft and deproteinized anorganic 
bovine bone. Ann Maxillofac Surg. 6(2): 165-171.

Bauer TW, Muschler GF (2000). Bone graft materials. An overview of the basic science. Clininical Orthop Relat Res. 371, 10-27.

Buckwalter JA, Einhorn TA, Marsh JL, Gulotta L, Ranawat A, Lane J (2006). Bone and Joint Healing. In RH. Bucholz, Rockwood And Green's Fractures In Adults. 7th Edition. 298 - 303). USA: Lippincott Williams \& Wilkins.

Conway J (2010). Autograft and nonunions: morbidity with intramedullary bone graft versus iliac crest bone graft. Orthopaedy Clinic North America. 41(1): 75-84.

Da Silva FOG, Ozawa TO, Bachega C, Bachega MA (2013). Reconstruction of alveolar cleft with allogenous bone graft: Clinical considerations. Dental Press Journal Of Orthodontic. 18(6): 138-147.

De Long WG, Einhorn TA, Koval K (2007). Bone grafts and bone graft substitutes in orthopaedic trauma surgery: A critical analysis. The Journal of Bone and Joint Surgery. 89(3): 649-658.

Dimitriou R, Jones E, McGonagle D, Giannoudis PV (2011). Bone Regeneration: Current Concepts and Future Directions. BMC Medicine. 9(66): 1-10.

Dimitrioua R, Mataliotakis GI, Angoules AG, Kanakaris NK, Giannoudis PV (2011). Complications following autologous bone graft harvesting from the iliac crest and using the RIA: A systematic review. International Journal Care Injured, 3-15.

Elsalanty ME, Genecov DG (2009). Bone grafts in craniofacial surgery. Craniomaxillofacial Trauma \& Reconstruction. 2(3): 125-134.
Ferdiansyah J, Rushadi D, Rantam FA (2011). Regeneration of massive bone defect with bovine hydroxyapatite as scaffold of mesenchymal stem cells. JBP. 13(3): 179-195.

Goudy S, Lott D, Burtom R, Wheeler, Canadi J (2009). Secondary alveolar bone grafting: Outcomes, revisions, and new applications. Cleft PalateCraniofacial Journal. 46(6): 610-612.

Greenwald AS, Boden SD, Goldberg VM, Yaszemski M, Heim CS (2006). Bonegraft substitutes: Facts, fictions, and applications. The Journal of Bone and Joint Surgery, 83-A(2): 98-103.

Holmes RE, Bucholz RW, Mooney V (1986). Porous hidroxyapatite as a bone-graft subtitute in metaphyseal defects. The Journal of Bone and Joint Surgery. 68-A(6): 904-11.

Hopper RA, Cutting C, Grayson B (2007). Cleft lip and palate. In H. Charles, Grabb and Smith's Plastic Surgery Sixth Edition. USA: Lippincott Williams \& Wilkins.

Hung N (2016, June 28). Basic Knowledge of Bone Grafting. Retrieved from In TechOpen: http://www.intechopen.com/books/bone-grafting/basicknowledge-of-bone-grafting.

Kinderlan JD, Nashed RR, Bromige MR (1997). Radiographic assestment of secondary autogenous alveolar bone grafting in cleft lip and palate patients. Cleft Palate-Craniofacial Journal. 34(3): 195-198.

Marzoeki D, Jailani M, Perdanakusama DS (2002). Tehnik pembedahan celah bibir dan langit-langit. Cetakan Pertama . Jakarta: CV. Sagung Seto.

Myeroff C, Archdeacon M (2011). Autogenous bone graft: donor sites and techniques. Journal Bone Joint Surgery America. 93: 227-36. 
Nascimento C, Issa JPM, Oliveira RR, Iyomasa MM, Siéssere S, Regalo SCH (2007). Biomaterials applied to the bone healing process. Int. J. Morphol. 25(4): 839-846.

Oberoi S, Chigurupati R, Gill P, Hoffman WY, Vargervik K (2009). Volumetric assessment of secondary alveolar bone grafting using cone beam computed tomography. The Cleft Palate Craniofacial Journal. 46(5): 503-511.

Peamkaroonrath C, Godfrey K, Chatrchaiwiwatana $S$ (2011). New clinical method for alveolar bone graft evaluation in cleft patients: A Pilot Study. Cleft Palate-Craniofacial Journal. 48(3): 286-292.

Steinberg B, Chiego DJ, Huizinga PJ (1999). Effect of human bone morphogenetic protein 2 implant on tooth eruption in an experimental design. Journal Craniofacacial Surgery. 10(4): 338-341.

Vogens E, Jones NF, Huang JI (2005). Healing of citical sized defect in the rat femur with use of a vasvularized periosteal flap, a biodegradable matrix, and bone morphogeneric poteins. Journal Bone Joint Surgery. 87(6): 1323-1331.

Vuletic M, Knezevic P, Jokic D, Rebic J, Zabarovic D, Macan D (2014). Alveolar bone grafting in cleft patients: from bone defect to dental implants. Acta Stomatologica Croatia. 48(4): 250257.

Wang Y (2003). Collagen-hydroxyapatite microspheres as carriers for bone morphogenics protein-4. International Society for Artificial Organ. 27(2): 162-8.

Wiedel AP, Svensson H, Schoenmeyr B, Becker M (2015). An analysis of complications in secondary bone grafting in patients with unilateral complete cleft lip and palate. Journal of Plastic Surgery and Hand Surgery, Early Online: 1-5. 